Environmental Justice in Community Garden Policy: Creating more accessible, welcoming spaces for newcomers in Canada

by

Erin Bergeron, BA, McGill University, 2016

A Major Research Paper

Presented to Ryerson University

In partial fulfillment of the requirements for the degree of

\author{
Master of Arts \\ in the Program of \\ Immigration and Settlement Studies
}

Toronto, Ontario, Canada, 2018

(C) Erin Bergeron 2018 


\section{AUTHOR'S DECLARATION FOR ELECTRONIC SUBMISSION OF A MAJOR RESEARCH PAPER (MRP)}

I hereby declare that I am the sole author of this Major Research Paper. This is a true copy of the $\mathrm{MRP}$, including any required final revisions, as accepted by my examiners.

I authorize Ryerson University to lend this MRP to other institutions or individuals for the purpose of scholarly research.

I further authorize Ryerson University to reproduce this paper by photocopying or by other means, in total or in part, at the request of other institutions or individuals for the purpose of scholarly research.

I understand that my MRP may be made electronically available to the public.

\section{Erin Bergeron}




\title{
ENVIRONMENTAL JUSTICE IN COMMUNITY GARDEN POLICY: HOW TO CREATE MORE ACCESSIBLE, WELCOMING SPACES FOR NEWCOMERS IN CANADA
}

\author{
Erin Bergeron \\ Master of Arts, 2018 \\ Immigration and Settlement Studies \\ Ryerson University
}

\begin{abstract}
This paper presents a critical review of scholarly literature discussing the relationship between community gardens and newcomers in Canada using an environmental justice framework. Specifically, this paper focuses on how the creation of a community garden policy can lead to community gardens being more socially inclusive spaces for newcomers. The numerous social and health benefits of community gardens are discussed in order to illustrate the need for continued research to focus on creating positive spaces within community gardens for newcomers. An examination of how environmental justice can affect considerations for policy creation and the implications the policy can have on newcomers' use of a garden will also be conducted. Based on the research, recommendations on how municipalities can use community gardens as tools for integration are presented.
\end{abstract}

Key words:

Community Garden; Environmental Justice; Newcomers; Canada; Hamilton, Ontario 


\section{ACKNOWLEDGEMENTS}

I would like to thank my supervisor, Dr. Cheryl Teelucksingh for her continuous support and thoughtful assistance during this process. I would also like to thank Dr. Mustafa Koç for his support as a second reader.

I am also immeasurably grateful to my colleagues in the program, without whom I would not have made it through this process.

Finally, I would like to thank Aileen, James, and Connor, for their unwavering support, encouragement, belief in me, and willingness to always lend an ear when I needed it throughout the completion of this degree. 


\section{TABLE OF CONTENTS}

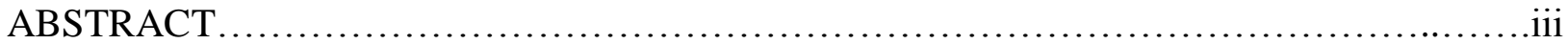

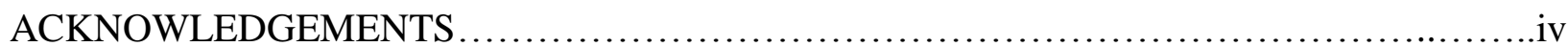

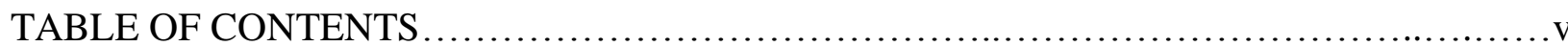

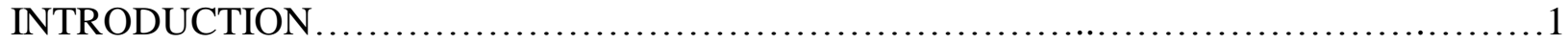

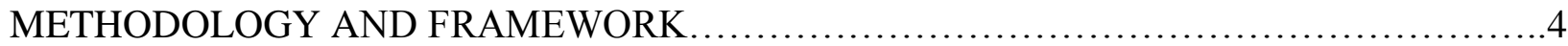

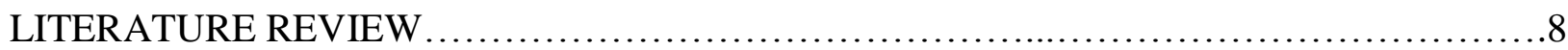

Community Gardens ..................................................... 8

Social Inclusion in Community Gardens.................................. 16

Policy \& Community Gardens....................................................21

Municipal Community Garden Policy Creation...............................21

Hamilton, Canada.......................................................23

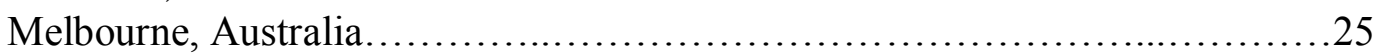

Difficulties in Policy Creation.................................................. 27

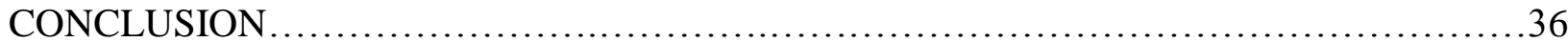

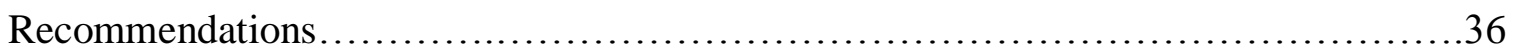

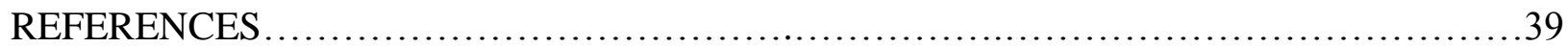




\section{INTRODUCTION}

Community gardens are becoming more prevalent across Canadian cities and the benefits that they bring with them are well researched. This paper will seek to understand how community gardens are spaces of inclusion for newcomers. Specifically, I am going to argue that policies informed by environmental justice framework will make community gardens more accessible to newcomers. Community gardens can be an important space for social inclusion and tool for integration of newcomers and will empower them by providing an opportunity to use their cultural knowledge and skills in Canada. The ways in which community gardens can help facilitate newcomer integration are numerous and include social inclusion, (Ghose \& Pettygrove, 2014) exchange of cultural knowledge, (Shan \& Walter, 2015) and a space for democratic inclusion regardless of citizenship status, (Emmett, 2011) among many others.

Community gardens can be used as social and cultural places to gather and exchange thoughts, ideas, and relationships. (Shan \& Walter, 2015) Even more, they can allow sustainable practices to flourish and be exercised by the community. For newcomers, this may mean learning about sustainability practices in Canada from other gardeners, while exchanging their own knowledge of sustainable practices with their new neighbours. Ideally, this work can be further built upon in order to more meaningfully engage with the intersection of Canada's ever-growing immigrant population and environmental concerns and issues. Further, we can use community gardens as a tool for amplifying diverse voices and ensuring that people with a multitude of backgrounds are able to participate.

Community gardens vary in many ways; they may be municipally sponsored or privately

run by community or non-governmental organizations, they may function primarily as spaces for hobby gardening or they may contribute to the alternative food movement by being a source of 
subsistence gardening. Whatever the reason, they have been proven to be spaces that foster social cohesion and provide a welcoming space for a diverse community. (Veen et. al., 2015) The creation of space where everyone is welcome can be a way to encourage members of the community who may not otherwise interact, to come together to focus on a shared hobby or interest: gardening. Participants are likely to form relations with each other through see one another at the garden, as well as offer each other mutual help in attaining their gardening goals.

Understanding the benefits and shortcomings of community gardens, particularly for newcomers, will allow municipalities to better create policy that will nurture inclusive and welcoming spaces for meaningful integration. Particularly in Canada, where newcomers are such a large portion of our population, and only becoming an even larger percentage, understanding how to support and create spaces for this growing demographic that will be inclusive and diverse will facilitate social integration. The impact that a community garden can have for a newcomer when they are settling into their new neighbourhood shows us that the many benefits deserve consideration and further research by policy makers. This includes effective policy to ensure that the space is used efficiently and equitably by all. Further research should be done on how policy can contribute to creating this space for newcomers.

Community gardens present a space where diversity can thrive, and many different forms and sources of knowledge are encouraged. They are a space where Canadian values of integration and acceptance can flourish. As such, we should critically examine the ways in which we create policy for community gardens in order to allow this to continue and hopefully build upon a solid base. Knowledge regarding community gardens is vast and can use a wide variety of frameworks to examine ways in which they are beneficial to a community and track the exact ways in which 
they can ameliorate the surrounding areas. This paper aims to examine environmental justice as a viable framework for creating fair and equitable community garden policy for newcomers.

Using examples of municipalities in Canada and Australia which have created community garden policy this paper will demonstrate that there is a societal demand for community gardens, they provide a unique way for social inclusion to occur, and that further policies on community garden should be created. A review of the relevant scholarly and policy literature discussing environmental justice, community gardens, and how this relates to newcomers follows below. Finally, recommendations on how municipalities can help to create the most beneficial community gardens for newcomers are presented. 


\section{METHODOLOGY AND FRAMEWORK}

The intention of this research paper is to examine the positive effects of community gardens for newcomers in Canada. Further, an examination of the ways in which environmental justice can positively affect policy creation to ensure that community gardens in municipalities are created to be inclusive and welcoming spaces for all is reviewed. To accomplish this, a review of relevant scholarly literature has been conducted. Following that, the process of community garden policy creation is examined in order to determine the ways in which environmental justice can and should be considered when creating a policy.

The decision to use newcomers in Canada as a population more generally, rather than focusing on one particular group of newcomers, is due to the broad nature of the scope of this paper. The intent is not to examine how a group from a particular background can benefit from community gardens, but rather, how the interaction of many diverse people in a garden can strengthen relationships and build community. Further research is needed in order to understand how different groups use community gardens and the ways in which policy can be applied to assure that gardens are spaces where environmental justice flourishes.

Finally, a review of how municipal community garden policy from the perspective of newcomers from both Canada and Australia is done as a means of contextualizing environmental justice vis-à-vis community gardens in Canada with recommendations provided for future research.

\section{Environmental Justice}

As Schlosberg (2007) is quick to point out, there are many different definitions that fall under environmental justice and this is partially due to the dichotomous nature of the term 'justice'. Holifield (2001) contends that having a multiplicity of definitions of environmental justice is useful, particularly when considering that different geographic, historical, political, and 
institutional contexts will lend to differing definitions of environmental justice. "Instead of regarding the lack of universal definitions as a barrier to progress, however, we need to treat the breadth and multiplicity of interpretations as guides to more relevant and useful new research.” (Holifield, 2001, p: 78) Therefore, environmental justice used throughout this paper must be thought of in the context of community gardens in Canada.

\section{Environmental Justice Theory}

When thinking about justice, we think of situations that are either just or unjust, and they are therefore either good or bad. Justice is often thought of as an individual concept, rather than one that applies to a group or community. However, environmental justice emphasizes collective, rather than individual action-consequence justice. (Scholsberg, 2005) Some scholars view environmental justice as being more directly linked to the environment that certain populations reside within, and how this can manifest different degrees of racism and classism. Gosine and Teelucksingh (2008) argue that "environmental justice addresses a wide range of social and environmental problems and seeks to eliminate harmful practices $[\ldots]$ " (p: 11) In this vein, environmental justice as a theory is meant to be more inclusive than traditional notions of environmentalism that have a perception of being solely for white and middle-class communities.

Distributive and procedural justice are part of environmental justice; these forms of justice allow for environmental justice to be possible. Procedural justice is borne out of desire to challenge the idea that justice can only be achieved through equitable distribution of resources; instead, an examination of the reason behind why distributional inequalities currently exist, and what powers have allowed them to exist must be critically examined. (Scholsberg, 2005) In this sense, environmental inequalities, such as sites of hazardous materials (i.e. garbage disposal sites) being historically disproportionately placed in or near low income communities, need to be examined 
from the point of what structures are in place that allow this injustice to occur. (Young, 1990) Environmental justice focuses on procedural and distributive justice in order to remedy particular forms of inequalities related to environmental factors. Distributive justice focuses on the equal and equitable distribution of resources, which is important for community gardens to ensure that all Canadian residents, including newcomers have access to these spaces.

As environmental justice was able to continue to grow and gain more attention from grassroots organizations and scholars alike, many scholars were able to shift focus from the broad discussions of environmental inequality. In this sense, environmental inequality refers to documented "disproportionate environmental burdens faced by racial and ethnic minorities and low-income households.” (Boyce, Zwicki \& Ash, 2016, p: 114) Environmental justice aims to remedy these injustices using procedural rights and distributional rights to ensure that proper consideration and attention is giving in planning stages of policy to properly avoid future injustices.

More contemporary research on environmental justice is able to widen the breath of its focus. What began as grassroots efforts that led to environmental justice in specific communities, there is now space to examine both smaller communities, or communities-within-communities as well as large-scale political efforts thereby challenging economic and political status quo that are responsible for environmental injustices. (Gibson-Woods \& Wakefield, 2012) The growth of environmental justice as both a movement and an area of research has led to a wider range of research able to be done. This has in turn paved the way to be able to examine more niche communities and phenomenon. Namely, community gardens can be examined as its own entity through an environmental justice lens. (Jermé \& Wakefield, 2013) Environmental justice applied as a framework to examine community gardens means looking at the ways in which policy is 
formed (procedural justice) as well as how the community gardens and the resources allocated to them are used (distributive justice). Focusing on "the everyday: the mundane and ordinary spaces in which we live, work, and play, and the micro-politics that create these spaces" (Jermé \&Wakefield, 2013: 296) has become a more substantial part of environmental justice research and examining community gardens in this paper aims to contextualize environmental justice on a micro scale within our own cities and neighbourhoods. Using an environmental justice framework to examine community gardens allows us to see the potential in creating better, more welcoming spaces for newcomers. In these spaces, newcomers can participate in and contribute to a sustainable food movement from a welcoming community-oriented environment.

The theoretical framework of environmental justice will be used as a lens through which to examine the literature throughout this research. The reason for using environmental justice as opposed to environmentalism or sustainability more broadly is that the environmental justice movement is largely seen as a more inclusive effort that intends to incorporate a myriad of voices. Much of the criticism of environmentalism has been that is it too white and too elite. (Bullard, 1994) The environmentalism framework has a historical tendency to forego the social impacts that environmental issues can have on marginalized communities. 


\section{LITERTURE REVIEW}

In order to provide context for the relationship between Canadian newcomers, community gardens, and environmental justice, a critical review of scholarly literature pertaining to these concepts has been conducted. The focus of this literature review is to examine newcomers' use of community gardens through an environmental justice lens. Further, gaining an understanding of how environmental justice can be used as a framework when developing community garden policy and its benefit to newcomers in Canada will be explored.

\section{Community Gardens}

Community gardens have been prevalent in North American cities and urban centres and have grown in popularity alongside the growth of cities. (Hondagneu-Sotelo, 2015) Community gardens are communal spaces where members of the community can garden alongside other members of the community who share this interest. Originally, their purpose was geared towards food production and achieving food security. Community gardens became even more of a tool for food security during times of economic hardship or war. (Pudup, 2007) Community gardens gained their popularity at the turn of the twentieth century by middle-class communities attempting to create transformations in schoolyards or urban communities which typically served marginalized populations. (Hondagney-Sotelo, 2015) These gardens were not originally created because of a desire to create a more vibrant and inclusive space where members of all communities could gather. Rather, they were created in an effort to aesthetically uplift areas that were seen as "a threat

to social order and national identity" (Pudup, 2007, p:1230) because of how many immigrant, poor, and working-class people lived in these communities in new urban centres. 
It was not until the 1970's when community gardens became more widely used as a tool for sustainability. As public awareness and concern for the environment has continued to grow, community gardens became a more commonplace. (Hondagneu-Seto, 2011) Further, as community gardens have evolved and expanded in popularity, they have become more opening spaces, particularly to diverse groups of people from a wider variety of cultural backgrounds. (Gibson-Wood \& Wakefield, 2012) This is not to say that all community gardens are perfect spaces of acceptance, diversity, and social justice, but as a whole, community gardens are increasingly becoming tools for environmental justice in urban centres, particularly for newcomers. Gardens are being placed in spaces where newcomers are more likely to resides (i.e. high-density areas), there is an opportunity to grow and cultivate a variety of plants, and an encouragement to share and exchange knowledge with fellow gardeners, including bringing previous gardening knowledge that a newcomer may have from their previous country. (Hancock, 2001) For newcomers who may not know where to get started in gardening in Canada's harsh climate, there are workshops and organization to get started in learning about gardening in Canada's climate. (Hamilton Community Garden Network, 2015) It is unlikely that any two community gardens would have the same demographics, social or democratic organization, or even goals. This paper seeks to examine community gardens broadly in order to understand how they can be used as a space where environmental justice can flourish particularly amongst newcomers in Canada.

Community Gardens, according to the city of Toronto, are spaces where groups of people can cooperate with others to grow their own plants. (City of Toronto, 2018) These spaces are often used as a place to encourage integration for newcomers and to foster social inclusion. (Agustina \& Beilin, 2012) Gardeners are often encouraged to plant vegetables, fruits, or plant species that they may have planted in their home country. This makes community gardens a space for 
multiculturalism and cooperative learning. (Baker, 2004) "Gardens come in various shapes and sizes; amongst other factors, they are cultivated by different types of communities in different locations, consist of individual or communal plots and may or may not require participants to garden." (Veen et. al., 2015: 1272) Further, community gardens can vary in terms of whether they are communally worked, or whether they offer employment, and hire employees to tend to the upkeep of the garden on a regular basis. The organization of the gardens can vary greatly from being one that offers individual plots wherein certain people are solely responsible for that plot exclusively, or they can be more communal, and the community can tend to any part of the garden that they see fit. (Wakefield et. al., 2007) In cities such as Toronto, participants may also choose to apply for a space at an allotment garden, the difference being that these spaces are more specifically for growing larger quantities of food. Larger plots may be ideal if the goal is to produce food for oneself or for entrepreneurial reasons, such as selling produce to a farmers' markets or local restaurant, for example. (Emmett, 2011) Allotment gardens in Toronto have fees ranging from $\$ 79.55$ for outdoor allotments to $\$ 336.74$ for indoor locations. (City of Toronto, 2018b) This paper does not seek to limit or exclude a particular type of community garden whether it be sponsored or created by the municipality in which it has been created, or whether members of the community have created this community garden in a less regulated, more grassroots fashion.

Pudup (2008) argues that community gardens vary considerably, and therefore the definition of community garden is quite broad. Pudup highlights three major ways in which community gardens differ from each other. First, community may refer to a group of people who live in the same small geographic area, or it may refer to people who reside in the larger municipality. It may also refer to a group of people with a common interest, such as religion, or that common interest may simply be gardening. (Ghose \& Pettygrove, 2014) Second, some 
gardens have individual plots in which specific people are responsible for specific plots of cultivable land. Third, some gardens produce food or flowers that are consumed or harvested by the people who garden that land, whereas some gardens produce food that is then sold, for instance, at a local farmer's market. (Pudup, 2008) Understanding that there are a variety of different types of community gardens with different purposes is an important reminder that there is not one uniform way to participate with a community garden.

An aspect of community garden that is especially related to newcomers is the ability to grow a variety of different foods in a garden. Growing different foods to sustain themselves or to be able to eat foods similar to what people have eaten in their home country is a way of exercising environmental justice. Baker uses the term "food citizenship" (2005, p: 305) to illustrate how newcomers are using community gardens to help cultivate foods that are important to them and are thereby transforming the space around them. This contributes to the community food-security (CFS) movement. The CFS movement allows gardeners to take ownership of the land and challenge many norms that are come along with immigrating to a new country. This not only includes challenging corporate food systems, but also allows them to connect to other people in their community by way of sharing knowledge and culture. Newcomers in Canada "bring local knowledge from around the world and adapt it to urban gardening spaces." (Baker, 2005, p: 307) The use of community gardens as a space to grow and cultivate food from a person's home country is an implicit form of environmentalism because it fosters a sense of responsibility and caring for the community and by extension, the environment. Particularly, if gardening and/or farming practices are more sustainable in one's previous country, the exchange of knowledge that occurs as a community garden has the opportunity to inform and improve on Canadian gardening practices. The alternative food movement gives space for marginalized and diverse voices to 
become more present and amplified. (Nouri-Sabzikar, 2016) Community gardens can "provide an alternative to food welfare reductions, urban food insecurity, environmental degradation, and urban disinvestment." (Ghose \& Pettygrove, 2014, p: 1094) This can also lead to healthier eating and some community gardens provide workshops or courses on gardening with the diverse foods that are produced in a community garden. (ibid.) A study by Gerodetti \& Foster (2016) shows that growing certain fruits or vegetables allows newcomers to maintain a link to their diasporic community "as well as integrate them into local growing cultures and traditions. In doing so, their growing practices contribute to the cultural landscapes of both established and migrant communities." (p: 817) The community gardens allow for newcomers to participate in environmental practices in an informal, implicit manner by encouraging production of food and transfer of knowledge: in this case, environmental justice practices because of the equality that. Community gardens are a space wherein diverse cultures and experiences are an asset that break down barriers between participants and allow for stronger relationships between them to grow. The common goal of participants in community gardens to help grow the garden as a whole creates a space where voices are amplified when they may otherwise not be. Community gardens are ruled by a democratic sense of desire to cultivate the most vibrant, healthy, and productive garden possible. The democratic nature of the community implicitly instills social justice in the garden, where many voices can be heard, and indeed are encouraged so that the garden can thrive. (Emmett, 2011; Smith \& Pangsapa, 2008)

Community gardens can be a space where immigration issues and environmental issues can intersect and interact. These two issues are increasingly important to our society as the number of immigrants in Canada continues to climb and sustainability efforts become more necessary. Often, these two issues do not have a chance to intersect, and findings show that on a large-scale, 
governmental platform, these two issues are rarely considered together. (Gibson-Woods \& Wakefield, 2012) The government of Canada devotes significant efforts to both immigration and environmental issues, but the two issues rarely intersect in a formal way. Community gardens in Canada are an excellent space for both issues to be examined both informally, especially by the people who participate in the gardening, and formally, by researchers. It is a physical space where we are able to see how environmental issues are regarded and looked at by newcomers, who represent a significant portion of people residing in Canada. With 21.9 percent of people reporting that they are or have ever been a landed immigrant or permanent resident in Canada in 2016, community gardens provide a space that can be used by any member of the community regardless of their status. (Statistics Canada, 2017) This makes community gardens spaces that can promote diversity and inclusion of different voices, which would inevitably lead to an assorted collection of ideas and knowledge about environmental issues and how to pursue environmental justice.

Using environmental justice while looking at community gardens allows us to examine the intersection of newcomers in Canada and environmental issues in a holistic and purposeful manner. Kurtz defines community gardens as "tangible arenas in which urban residents can establish and sustain relationship with one another, with elements of nature, and with their neighbourhood." (2001, p: 656) This definition highlights how the interaction of participants with each other and participants with the environment is intertwined to create an ideal space for environmental and social justice. Participants are encouraged to take a democratic approach to community gardening and ensure that all voices are represented and heard by providing a space where input on the focus and direction of the garden is considered, and even encouraging participation in local politics by groups writing to city councils together presenting their needs for garden spaces. (Shan \& Walter, 2015; Emmett, 2011) Through "constructing and maintaining 
place in the form of community gardens, groups may enact place-based collective identities and assert claims to space." (Ghose \& Pettygrove, 2014: p. 1098) For this reason, community gardens are an ideal space to welcome newcomers to a socially and environmentally conscious space wherein their voice and prior knowledge will be valued, and they become more environmentally just because of it.

Participatory action is well-illustrated in cases of community gardens. Gardeners are participating in and agreeing to the politics of each specific garden when they choose to garden in the plot that they do, even though they are gardening for a variety of different reasons. (Pudup, 2007) Politics in community gardens may refer to the "function as urban commons through which minority residents collectively produce space to resist or provide alternatives to capitalist social relations." (Eizenberg, 2012, as cited in Ghose \& Pettygrove, 2014, p: 1094) They become a part of the social community of that garden. It should, however, be noted that action need not be explicit. The reasons for community gardening are so varied and many that environmental justice is likely not what each gardener would state as their primary motivation for gardening. In this sense, environmental justice is a scholarly concept applied to an organic phenomenon. Three themes of participation that resonated strongly with newcomers according to Harris et. al., (2014) include land tenure, that is, the actual or perceived ownership of the land or garden plot by the newcomer, reconnecting with agriculture, and community belonging. These reasons for participation in community gardening are not done for explicitly environmental justice purposes, however, the community garden provides a space for environmental justice to flourish by allowing persons or groups who may otherwise be or feeling marginalized in Canada to claim a stake in their community. The inclusion of diverse peoples and the community that grows around the community garden is a key component of solidifying community gardens as spaces where 
environmental justice can flourish in an organic manner, going beyond the academic and scholarly into an implicit function of inclusive and equitable space.

Jermé \& Wakefield (2013) contend that attention must be given to the processes that are required for the formation of community gardens in order to properly understand and theorize environmental justice as it pertains to environmental justice. That is, the processes that allow community gardens to become municipally-sanctioned areas, that are on city-owned property. Community gardens created within an environmental justice framework would need to be formed based on knowledge and experience of those who live in the community or who have knowledge and expertise regarding that community. Efforts must be made to ensure that individuals and communities who may have historically been excluded from such planning efforts must be included as per procedural justice theories within environmental justice. This participation can also be a way to foster democratic participation in communities and groups that may not participate in more traditional forms of democratic participation (i.e. voting, working for elections, etc.) (Ghose \& Pettygrove, 2014) Democratic participation in this sense includes activities such as participating in discussions and plenaries surrounding the future of and plans for community garden lots. This becomes a form of civic engagement that is inclusive of the individuals and groups who are using this space and gives them a way to take ownership of it. In this sense, environmental justice is intertwined in the decision-making processes surrounding community gardens.

Community gardens are designed to serve the community at large in a multitude of ways. There are many different reasons people may join community gardens: to provide a communal space for people to engage in a fun hobby, a social activity, subsistence production, space for alternative food politics, or a place to participate in an environmentally conscious activity. (Holland, 2004) The garden may not be explicitly designed using an environmental justice 
framework. However, the main criteria for a community garden being a tool for environmental justice is that it would be open and accepting of marginalized populations or a wide variety of people who wish to participate in the garden.

\section{Social Inclusion in Community Gardens}

Studies have shown that community gardens have many health benefits that promote participant welfare in a holistic manner. Benefits of community gardens include better access to food and more nutritious diets, participants show an increase in physical activity from gardening, communities in which the gardens are have reports of higher safety and security, community development becomes a higher priority, and a higher appreciation of cultural diversity and strengthening of community social connections. (Wakefield et. al., 2007) Using an environmental space such as a community garden to promote and encourage diversity and social inclusion, helps to encourage the successful participation in an environmental and social movement by newcomers. These forms of exclusion have included "economic marginalization; (in)accessibility of typical avenues of participation; narrow definitions of "environmentalism" among environmental organizations; and the perceived whiteness of the environmental movement." (Gibson-Wood \& Wakefield, 2012, p: 641) Egoz \& Nardi (2017) posit that "community gardens facilitate social cohesion and intercultural dialogue [...] and inclusive ideas of citizenship" (p: S78) In the multicultural context of Canada, this provides a useful tool for social inclusion in a safe space that allows both newcomers and other community members to build positive relationships and learn from one another.

A study by Hartwig \& Mason (2016) conducted in Minnesota showed that community gardens negated many of the feelings of social isolation faced by newcomer women particularly. This study provides insight into the gender differences in community gardens, particularly 
regarding the reasons why newcomer women participate in community gardens and what they like about them. The findings show that newcomer women enjoyed the gardens because it provided a space for children to play safely outside while the adults tended to the garden. Additionally, it was reported the newcomer women interviewed suggested that the value of the garden was that it helped alleviate social isolation and depression. (Hartwig \& Mason, 2016) Newcomer women tend to experience social isolation at a higher rate than newcomer men because they are more likely to stay at home to take care of their family, either due to language barriers or high cost of childcare. (ibid.) Therefore, community gardens provide a space where women who may not have found the chance to do so otherwise can socialize with other community members, and hopefully grow food or plants that are important to them, giving them a sense of belonging. Participants in this study reported that they "felt powerful" when they shared their knowledge and produce with other community members. (Hartwig \& Mason, 2016, p: 1156) The respondents to this study were American, but these results show us that the respondents may not be the primary breadwinner in their family. In Canada, because of the points-based immigration system, it is likely that the decrease of social isolation would be particularly helpful for family-class immigrants; women who came with members of their family and may not have the same employment opportunities. The community garden provides a way for these women to meaningfully interact with other members of their community and sustainable cultivate produce for themselves and their families.

Expanding on how community gardens can eliminate traditional forms of exclusion: there is often no fee to join or participate if the garden is run by a non-governmental organization or a church for example. For municipally sponsored gardens, the fee can be waived for low-income households, or persons with disabilities. (Ville de Montréal, 2005) However, the participant may likely be responsible for purchasing their own seeds and plants. The initial start-up of a community 
garden in Toronto requires funding in order to conduct soil tests, purchase tools, bins, fencing, and perhaps plant material, however the City of Toronto provides suggestions on where to obtain funding (for starting a garden, not for a joining an existing one). Acquiring the physical space for the garden requires submitting a proposal and application, but there is no direct cost associated with it. (City of Toronto, 2018b) This reduces the economic barrier for people to participate. Next, community gardens are designed to promote accessibility in environmental participation beyond traditional forms that may not be possible by having community gardens in communities wherein there is a higher rate of poverty of marginalized populations. (Wakefield et. al., 2007) This makes the space accessible in terms of physical proximity to where one resides, but also by ensuring that the garden is in a community or space where the participants feel comfortable. Third, participants of a community garden are there for a plethora of reasons and are therefore not confined to performing acts of environmentalism in a specific manner. Finally, as the name suggests, community gardens are meant to promote a sense of community. In many cases, gardens seem to be spaces wherein the shared interest of gardening and the democratic nature of planning and organizing the space promote a place where people of different ages, ethnicities, and socioeconomic status can collaborate. This has led to sense of community and wellbeing in many community gardens where there can be a "safe community space for multiple forms of socializing and recreation." (Ghose \& Pettygrove, 2014, p: 1101) Specifically for newcomers, a sense of community is gained by connecting to the land in their new country, as well as other gardeners with whom they interact. (Harris et. al., 2014) In a community garden, participants will exchange ideas and knowledge, and offer each other help with the garden, which in turn can create a more solid sense of community and belonging. (Veen et. al., 2015) 
Shan \& Water (2015) contend that "gardens are spaces for learning not only about gardening and local ecological conditions but also about sustainability, environmental consciousness, the politics of space, collective organization, social entrepreneurship, decolonization of place, and participatory democracy." (p: 22) This supports the idea that community gardens are spaces that facilitate integration into Canadian society and social cohesion among participants while giving gardeners who are newcomers a holistic experience of environmental justice in their community. There is no expectation that the newcomers conform to Canadian gardening practices, and in fact many report trying to cultivate plants and food that is native to their home country, or, since Canadian soil may be less forgiving than their home soil, finding an alternative that is similar to what they may have grown in the past. (Stewart, 2012) This allows newcomers participating in community gardens to explore their own identity in relation to gardening and Canadian agriculture in a way that encourages a diversity in knowledge within the community and is in line with Canada's multiculturalism policy.

Social inclusion and environmental justice go hand-in-hand because the promotion of the community garden as a space for everyone allows people to feel like they have a space they belong, while committing to environmental pursuits. Community gardens are not intended as spaces of assimilation or spaces only for Canadian-born people to pursue their hobbies or goals. Rather, they are spaces where newcomers can feel belonging, ownership, and eventually home. (HondagneuSotelo, 2017; Delind, 2002) The concept of community gardening promotes a space of no expectations, rather a space where decisions and planning can be done in a fashion that respects and encourages diversity of opinion. Social inclusion as a by-product of community gardening also does not necessarily need to be an explicit function, much like the pursuit of environmental justice that occurs. However, whether implicit or explicit, community gardens can be used as a 
tool for environmental justice by newcomers in Canada. Examining how environmental justice could be used to inform community garden policy in a municipality, as in Hamilton, will allow us to assess the benefits of environmental justice for newcomers in community gardens. 


\section{Policy \& Community Gardens}

It is important to consider how policy influences the creation of community gardens. Specifically, there is a clear and obvious impact on municipally-funded community gardens, but the consequences of these policies directly or indirectly extend into gardens that are not run by municipalities, such as community gardens that are run or funded by non-governmental organizations, like churches. An examination of the measures that can be put into place to effectuate environmentally just policy surrounding community gardens allows us to look at community gardens from a more top-down, bureaucratic perspective in order to gain a more comprehensive understanding of community gardens as a whole and where there is a possibility for improvement from a newcomer's perspective. An understanding of the policies informing community gardens and the process of their formation is important in allowing us to better comprehend community gardens from a wider perspective. That is, without looking at community gardens run by municipalities, it may be more difficult to understand how precisely using an environmental justice framework can create a better, more inclusive community garden for newcomers in Canada. In this case, attempting to use environmental justice as a methodology in creating policy for community gardens allows us to broadly examine the utility of environmental justice and how it can be improved upon.

\section{Municipal Community Garden Policy Creation}

The seventh principle of environmental justice states that "the right to participate as equal partners at every level of decision-making including needs assessment, planning, implementation, enforcement and evaluation." (Bullard, 2005, p: 300) Consultation in the creation of community garden policy, particularly from members of the public and groups that will use community gardens, is therefore a key priority. Although, the consultation throughout the entire process does 
not seem to occur in practice. For example, consultation was only possible until the policy is given to higher levels of bureaucracy where decisions must be made by city council and are not able to be amended without restarting the process in Hamilton, Ontario. (Jermé \& Wakefield, 2013) Environmental justice in relation to community gardens stresses the importance of communities having a voice in the placement and formation of gardens and ensuring that gardens are placed in areas that allow for equitable access. This requires collaboration from members of the public, members of the municipal government, and other partners to ensure that the plans and policies being made are fair, cooperative, and advantageous to all parties. A consideration that had to be taken into account in the initial stages of consultation was which spaces would be appropriate for municipally-endorsed community gardens to be placed. Obviously, the hope is that the garden will be placed in a space that is easily accessible by people of different backgrounds, ethnicities, and socio-economic status. (Emmett, 2011) However, an environmental justice framework is required to properly find these spaces because many of the spaces that would have been very accessible were deemed inappropriate because of "their greater density and historical and contemporary industrial activity (and therefore greater likelihood of land contamination, existence of pressures on land for alternative uses, and possibility for conflicting adjacent land uses." (Jermé \& Wakefield, 2013, p: 304) In short, in the case of Hamilton, Ontario, areas which were generally populated by lower-economic status populations were disproportionately ruled out as appropriate areas for community gardens to be placed. This would be inconsistent with an environmental justice framework, which means that additional considerations need to be made by municipalities on how they can ensure that community garden placement is equitable through public consultation and a commitment to ensuring equity. The placement of community gardens will affect who is able to use them and create a sense of place-belonging for gardeners. (Egoz \& De Nardi, 2017) 
Without using environmental justice as a framework, one might rule out spaces for community gardens which would prove especially beneficial for the populations surrounding them. (GibsonWoods \& Wakefield, 2012)

Food accessibility and sustainability would be one of the main reasons for a community garden being especially beneficial in low-income areas, as well as the social inclusion benefits that community gardens provide. (Emmett, 2011) Using environmental justice at each stage of the planning process and keeping in mind the communities that would benefit from them even if the physical space is not ideal according to the standards set out by municipal councils. For community gardens to thrive, they require a combination of experts, and that combination should include persons who are members of the community as well as persons who are interested in the social justice component of creating a community garden. Using environmental justice as a framework allows for a top-down government perspective to gain meaningful insight from people or groups with a grassroots, bottom-up perspective. (Pezzullo \& Sandler, 2007) Groups whose main interest in this case is the welfare of the people and community using the garden.

\section{Hamilton, Canada}

In Hamilton, Ontario, following public interest in building more community gardens and creating a network to further support gardens in their city, the Hamilton Community Garden Network (HCGN) in 2007 was established. In 2010, an official community garden policy was created with input from stakeholders and the Community Food Security Stakeholder Committee. Partnerships have included City of Hamilton Public Works, Public Health Services, and the Ontario Trillium Foundation as the largest partners, as well as many other smaller partnerships. (Hamilton Community Garden Network, n.d.) The HCGN aims to provide access to the tools and resources necessary to participate in or start a community garden, allow easy access to gardens by 
providing support in finding a community garden, such as online maps, as well as creating opportunity for learning and connection through workshops, community events, social media, and networking meet-ups. (Hamilton Community Garden Network, About Us, 2018) Jermé and Wakefield (2013) demonstrate how environmental justice was a consideration in the planning stages of this community garden policy, where they found that the consideration of this framework excelled, and where it fell short. This paper will build upon these findings to examine how these policies may be effective in regard to the promotion of newcomer participation in community gardens and how newcomer populations can be considered alongside policy decisions in regard to community gardens.

One of the main considerations in the mission of the HCGN is building an inclusive community; "people from all backgrounds can get engaged and share their skills and traditions in a safe gathering place" (Hamilton Community Garden Network, About Us, 2018). Nearly one quarter of Hamilton residents are immigrants; that the mission value of the HCGN reflects this demographic is important because it shows a commitment to creating a space for the people of Hamilton. (Statistics Canada, 2016) The proportion of the population that are immigrants would have an impact on how community gardens are used in Hamilton, and obviously by whom. The City of Hamilton has posted on its website that it is a welcoming city for newcomers; the city has included a section of how it has welcomed Syrian refugees, and on that webpage there is a link that newcomers can use to explore parks and recreation activities available in Hamilton, including information on how to get started in community gardening. (City of Hamilton, 2018) In theory, the diversity of the city and its claim to be a welcoming city should be reflected in the policies that are created surrounding community gardens. The merits of an environmental justice framework 
become apparent when examining the applicable benefits that the policy can have on building an inclusive community garden, which as previously mentioned are numerous for newcomers.

\section{Melbourne, Australia}

Melbourne has a very high population of residents born outside of Australia; 34.8 percent versus the national average of 26 percent. (Australian Bureau of Statistics, 2016) There is therefore great demand for services and tools that will promote and facilitate social inclusion for newcomers. One such tool that the municipality has sponsored is community gardens. The policy created for community gardens states that one of the benefits of a community garden and a reason for creating them is that they foster diversity and connection. The City of Melbourne community garden policy "encourages community garden groups to interact and engage with residents and volunteers from diverse backgrounds and knowledge bases." (City of Melbourne, 2013, p: 3)

Augustina \& Beilin (2012) examined whether community gardens in Melbourne are indeed spaces of integration and social inclusion for newcomers. They did not explicitly examine the community garden policy set forth by the city, but whether or not the gardens were spaces of social inclusion and diversity as the policy mandates, is explored. Their results showed a more mixed result than other studies have shown noting that barriers toward fostering meaningful relationships in community gardens still exist. Strengths of the community gardens included that there was an exchange of gardening techniques and seeds that occurred in the garden which strengthened feelings of connections to their country of origin as well as the connection to their fellow gardeners in Australia. Newcomer gardeners viewed the activity of gardening as an activity that promoted their social wellbeing and sense of self as their social status could be enhanced within the garden by interacting with other gardeners and discussing their produce. A study of Melbourne by Kingsley et. al., (2008) suggests that community gardens are spaces that are especially important 
to restorative community-building efforts suggesting that community gardens could help ease tensions in the area over diversity. This tension could perhaps be a reason why community gardens in Melbourne seem to receive less glowing results for newcomers than other studies found in this paper.

Barriers noted in Melbourne pertained to language aptitude. Augustina \& Beilin (2012) remarked that many gardeners still faced challenges in developing new relationships when their English language skills were not very high. Relatedly, Kingsley \& Townsend (2006) noted that the majority of the advertisements for where community gardens were and how to find them in Melbourne were in English, and that this led to community gardens being not as culturally diverse as they could be.

Perhaps a consideration for a municipality that explicitly states their intent to have culturally diverse community gardens where multiculturalism can thrive should be to promote their gardens in media that is not predominantly consumed by Australian-born people. It is not enough to include diversity in a policy if there will not be tangible efforts to carry out the task. The lessons learned pertaining to language barriers in Melbourne community gardens can be applied to other municipalities. The benefits of a community garden have already been established and their potential benefits for newcomers specifically have also been highlighted. Community gardens as a tool for social integration provide holistic benefits that may not be possible using other integration spaces. These include the aspect of food sustainability and place-belonging that have been mentioned. Accessibility of community gardens must be considered, not just whether or not they will be welcoming once newcomers are participating, but they must be easily found and promoted to people who will benefit from them in a language that they know. 


\section{Difficulties in Policy Creation}

According to Jermé \& Wakefield (2013), in Hamilton, once the first draft of the community garden policy was created, it became very difficult to modify, particularly if the party interested in modifying the policy was not a senior-level member of city staff. This inhibits the process of ensuring that public consultation is taken into consideration. Granted, it would likely become an extremely long and tedious process to enact a policy if public consultation was encouraged after each modification or each round of revisions but a critical component of environmental justice nonetheless; to only have one possible time where perspectives outside of the councils are taken into consideration is a missed opportunity. Indeed, it was only the Public Works department that was responsible for drafting the policy. (ibid.) However, a commitment to public consultations is a key part of the procedural justice aspect of environmental justice and will ultimately make the garden and the policies informing it more representative of the community. Further collaboration with departments specializing in food security, social wellbeing, and physical health should have had a larger role to play to making community gardens a more holistic and environmentally just space. (Nouri-Sabzikar, 2016) Environmental justice "demands that public policy be based on mutual respect and justice for all peoples, free from discrimination or bias.” (Bullard, 2005: p: 300) One of the main lessons that can be learned from the examination of Hamilton's community garden policy is that greater collaboration between departments (as well as between government and public) would naturally allow for an increase in diversity of perspectives. Using the City of Hamilton council as an example, in 2018 , the council was almost entirely male and nearly entirely Caucasian; these demographics do not represent those of the city of Hamilton. (City of Hamilton, n.d.) Greater collaboration would allow for further representation of the diverse populations of municipalities such as Hamilton, as well as the input from the community to ensure that public 
policy in community garden be based on the aforementioned principles of respect and justice. Similar to the community gardens being enhanced through a variety of prior knowledge and experience, bringing a wider range of knowledges and discourses when creating the policy that implements and tends to the gardens will only enhance their success. (Baker, 2004) There is already plenty of literature citing the numerous benefits of community gardens, but perhaps future research can examine the efficacy of having an inter-departmental approach to policy making of community gardens. (Veen et. al., 2015; Pudup, 2007; Hancock, 2001)

Of course, cost would also be a factor that needs to be considered in this situation. Unfortunately, as is that case with any sort of community building project, good intentions and valuable insights are often cast away because they would cost more than the project is able to handle. The cost of lengthening the consultation process and continuously getting city councillors to review the changes and suggestions made to the policy would increase the cost of the project, which ultimately would leave less resources available for the community garden itself. As an already economically strained project, community gardens in Hamilton and indeed across Canada need to be especially budget-conscious. (City of Hamilton, 2011) The decision to only have the policy available for public consultation rather than continuous revision allows more money to be spent on tools, resources, events, and ideally hiring a community garden coordinator. In Hamilton, when the community garden policy was officially created, it was not created as its own component of the overall city budget, but rather it was written into the Public Works department as part of their budget (Jermé \& Wakefield, 2013). By placing the community garden policy as an item in the Public Works department budget, there may be an increase of support for community gardens because there is a larger department that can provide the administrative backing and experience 
for the program. However, it also diminishes the overall autonomy and importance afforded to the policy.

Creating policy surrounding community gardens is an especially difficult task when they do not generate a profit; they are spaces that have proven health and social benefits, yet there is very little economic benefit to the municipality since the only profit comes from the fees collected. (Corrigan, 2011) For gardeners, produce from the garden is sometimes sold to farmers' markets, typically through informal channels, but that is the extent to how the garden is likely to be profitable. (Pudup, 2007) The garden may provide produce for the gardener and may therefore save them money at the grocery store, but there is no evidence that community gardens provide a way to make a liveable income. Therefore, even though it has been proven that community gardens have numerous positive social and physical effects, community gardens may not receive the assistance and resources necessary to thrive because their value is difficult to quantify in monetary terms and unprofitable according to neoliberalized standards of profitability. Community gardens provide increased social capital and appreciation of social diversity, which is certainly beneficial to any newcomers who use or participate in community gardening. (Hancock, 2001) These benefits would undoubtedly improve the lives of those who participate in community gardens and reap their benefits, but these benefits do not provide tangible monetary gains. It could be surmised that increased feelings of social inclusion and more chances to participate in a community event, some scholars contend that gardening is "less about gardening than they are about community." (Glover et. al., 2005, p: 5) This implies that the real gain from community gardening comes from the increase in social network connections and social capital as a result. However, once again, this would be difficult to quantify and therefore potentially not a top priority for a municipality. Community gardens will likely remain a line in a budget within a department constantly struggling 
for the resources they require. As Jermé and Wakefield (2013) point out, one solution would be to increase funding for community gardens from non-governmental organizations, but this runs the risk of allowing external bodies the ability to impose their own agenda onto a community garden. For this reason, creating policies for community gardens consistent with an environmental justice framework is not a simple task, and is in fact one that requires creative thinking and an incredible amount of dedication to pursue completely.

Examples of injustices that can be prevented before they materialize through thoughtful consideration in the creation of a community garden policy include issues such as placement of community gardens. Community gardens that are not in close proximity to, or adjacent to the homes of gardeners were used more frequently than community gardens that were not adjacent to gardeners. (Wakefield et. al., 2007) This indicates that the placement of gardens will indicate very strongly who will use each garden. Ideally, gardens would be placed in easily accessible locations in a municipality so that people from every community would be able to participate in gardening. However, as mentioned before, given that financial resources are a constraint, the placement of community gardens needs to be given significant consideration. Further, as Wakefield et. al. (2007) note, there is an increase of activity in the community gardens observed during the evening hours which could that the people participating in these gardens hold jobs or other obligations during the daytime. Production of food in community gardens, rather than gardening of flowers and other non-edible plants, is more likely to occur in community gardens in low-income areas. (Kremer \& DeLiberty, 2011) The deduction made from these observations could be that since it appears that the participants of community gardens are of working class, then the policies created surrounding community gardens should reflect this population. Having an understanding of who will use a 
community garden and what their specific needs are will help to create more inclusive and accessible gardens.

Aside from financial concerns, other obstacles to creating policy for community gardens using an environmental justice framework include overall misunderstanding or reluctance to consider the implications of using environmental justice as a framework - particularly as it pertains to equity. Environmental justice requires procedural justice, as procedural justice encourages equitable outcomes in policy from the early stages of planning a community garden. (Brulle \& Pellow, 2006) Procedural justice is a necessity in environmental justice because of the focus on the process that leads to a policy being created and the careful examination of whether or not this procedure makes space for an equitable policy to be created at all. As previously mentioned, when looking at which spaces are appropriate to support a thriving community garden, there are many topographical considerations that need to be made. By incorporating procedural justice into this planning stage, researchers would be more inclined to see beyond the geography and examine "the forces that generate, stabilize, or even naturalize spaces of inequality and injustice." (Holifield, Porter \& Walker, 2009, p: 599)

The use of environmental justice as a framework in community garden policy allows those who hold privilege (such as city council politicians) to critically examine the ways in which areas of exclusion can be transformed into areas of inclusion. Smith \& Pangsapa (2008) contend that "effective policy depends on changes at all levels of society" (p: 4) and that those with power must understand the positive ethical implications of environmental justice in policy. It has been argued that "the success of the environmental justice movement has been limited by the fact that it seeks change via status quo political and economic systems, putting faith in the status quo to remedy problems, thus supporting the status quo and impeding genuine systemic changes." (Gibson-Wood 
\& Wakefield, 2012; Benford, 2005) In this sense, it would require actors of varied status to consider where community gardens should be placed, who they should be designed for, and how they can accommodate diverse populations. For this reason, municipalities need to be made aware of the benefits of community gardens for social integration and further research should continue to examine the positive effects that a community garden policy can have on integration of newcomers. Using environmental justice as a framework for policy means that it is understood that newcomers may have different needs in practice in a community garden. Their inclusion and participation in the garden requires the understanding at the outset of policy making that cognisance of diverse needs and uses will naturally occur in a community garden and the goal should be to make these spaces as inclusive as possible. Consultation with newcomers on how they plan to or how they already use community gardens would disrupt the status quo of actors involved in the creation of policy. Namely, by conducting research asking the people who are gaining the most benefit from community gardens what their needs are, we can gain a more comprehensive understanding of the ways in which community gardens can thrive for diverse populations. "[...] more opportunities for legitimate participation in environmental policy-making processes may provide environmental justice for all social groups.” (Gould \& Lewis, 2009, p: 139) By using procedural justice, an element of environmental justice in creating a community garden policy, municipalities can focus on preventing injustices before they happen, rather than attempting to repair them after the fact.

In this way, we see that the practical benefits of using an environmentally just framework in policy are only going to materialize when political actors and other actors with privilege provide the necessary support at the outset of the project. In order for community gardens to become and remain spaces for understanding and inclusion, there must be systematic efforts that ensure this is 
possible. The onus to continuously work towards this goal rests neither solely on policy makers and politicians, nor on the gardeners themselves, but rather through thoughtful collaboration of all stakeholders invested in the success of a community garden. Before a garden is fully formed, environmental justice should be used as a framework to determine the ways in which consideration can be made for how the garden can become a more equitable space for those who intend to use it. Ensuring that there is not an unequal distribution of space and gardens can allow municipalities to create a more inclusive space, bringing with it all the aforementioned benefits of community gardens for all populations but especially for marginalized communities. Critically examining who the space is designed for and who the space will benefit when placed in different locations is an excellent start to creating an equitable garden. Of course, this requires collaboration from multiple actors and organizations, and not unilateral decision-making from a city council, no matter how good their intentions may be. (Ghose \& Pettygrove, 2014)

Another way in which communities can ensure that they remain equitable spaces is by creating long-term leases for these spaces. Long-term land tenure is a concern among gardeners who may wonder whether their inclusion in this activity and space is only to be a short-lived experience. (Jermé \& Wakefield, 2013; Wakefield et. al., 2007; Harris et. al., 2014) When a community garden is placed on municipally owned land and sponsored by the city, there is often only a short-term lease that is granted for the community garden. The lease that is granted is likely able to be terminated given a short amount of notice, as well. (Schukoske, 2000) This can have a negative impact on the feeling of belonging and place-making that gardens would create, because they would have a harder time feeling as though this land truly belongs to them. The City of Vancouver is known for issuing longer leases (five years) or even longer if the garden is backed by a community outreach program or brings forth a long-term plan to city council by non- 
governmental organizations. (City of Vancouver, 2005) Another reason long-term leases would be a consideration of an environmental justice perspective is that gardens take time to properly cultivate - both in terms of plants - but also in terms of the trust and relationships that are grown in a garden. Community engagement can begin and flourish in community gardens and as such should be seen as spaces that will exist for longer periods of time. In order to give a sense of land ownership to those who care for it and the people who use it, longer leases create a stronger community. (Jermé \& Wakefield, 2013; City of Vancouver, 2005) The social networks that are created in community gardens would not be likely to happen immediately but would instead take time to materialize. Gardeners "ask about and learn about the vegetables that other cultures grow and use. It may not be long before this progresses to sharing recipes, sharing foods, establishing community dinners and in various ways building social networks across ethno-racial divides." (Hancock 2001, p: 279) This makes long-term leases in areas of social diversity especially important. Long-terms leases help those from all backgrounds see that this is a space of safety, comfort, and understanding. If the space is constantly fraught with impeding lease terminations, or if gardeners are constantly looking to relocate, the same cohesive groups that matriculated will be unlikely to survive.

Community gardens are places where people including newcomers can experience recreational activities in an autonomous manner. (Hondagneu-Sotelo, 2015) This means that there is no expectation of assimilation nor is there a requirement that newcomers must bring prior knowledge pertaining to gardening or agriculture. If newcomers do possess this knowledge, community gardens act as safe spaces to exchange information and form relations, but there is no requirement to do so. (Ghose \& Pettygrove, 2014; Shan \& Walter, 2015) Focusing on community gardens as autonomous spaces is important in throughout the process, but especially so in the 
planning stages. There should be an understanding that although the garden may rely on or require support from the municipal government, the garden should be understood as an autonomous space capable of self-determination and decision-making. As previously mentioned, community gardens are spaces of democratic participation and in this sense should be understood as democratic within the garden, rather than reporting to a bureaucratic or political body. Allowing the participants to be the experts regarding what is necessary for the garden to grow and thrive is important in allowing those voices to be amplified. Social inclusion and community building are more likely to occur when the garden has a greater amount of autonomy because it will necessitate that the participants to take ownership of the land and the responsibilities that come with it. This allows participants from any background to participate in the democratic engagement that occurs with community gardens and gain a sense of autonomy in their community regardless of economic or citizenship status. 


\section{CONCLUSION}

The review of the literature and the examination of municipal community garden policy show up that there are many different ways to ensure the success of a community garden as a space of integration and socialization. Since Canadian cities have increasingly higher immigrant populations, and that this trend is expected to continue upwards, it is critical to consider how safe spaces for integration can be created. Community gardens provide spaces where integration and social cohesion is not always the explicit purpose, but it is a phenomenon that occurs organically, and with help from municipal governments can be even more effective. The aspect of having a shared interest or hobby helps bring people together to find common ground on a topic that is relevant to their community. The ability to exchange knowledge and learn from one another helps community members get to know one another and foster meaningful relationships. Members of the community work together towards a common goal and are able to join a network of gardeners who rely on each other and gain a sense of trust from those in their garden. (Wakefield et. al., 2007) The benefits that community gardens can have on the community at large and particularly on newcomers should be considered by policy-makers; best practices should be furthered researched to maximize benefits of the garden. Below are some recommendations that can be used as a starting point creating meaningful spaces.

\section{Recommendations}

First, as community gardens are spaces designed to benefit members of the community, that is precisely who should be consulted on the garden, not only at the beginning of the process, but throughout. While there are some limitations on this, such as time and monetary resources, in order to design a space for a population, a deep understanding of what that population needs and wants is in order. Litt et. al. (2011) found that "the success of community gardens was largely 
dependent on strong neighbourhood leadership and outreach [...]" (p: 1470) Public consultation can be a difficult process that requires significant efforts from the local municipality, but the outcome is that you will have a space specifically designed for the population it is intended for. The consultation should include aspects such as where the garden should be placed, what sort of garden it will be, and what sorts of events and workshops would best benefit those who use the space. What should be prevented is that the community garden design and/or any policy relating to community gardens becomes entrenched in the bureaucratic systems of a city council. As previously mentioned, it became too cumbersome for public consultation to be continuously added to the discussion past the first stage. If the goal is to create a space that is for community members, then this should be factored into the plan of creating the policy; both in terms of time management and resource management.

Programs and workshops should be created with the knowledge and intention that they will be working with and for a diverse group of people. Given that the research shows how beneficial community gardens can be for newcomers in both forming new relationships with those, the benefit that newcomers bring to a community garden should not be overlooked. Newcomers may bring with them knowledge regarding garden, alternative food practices, or sustainability from their previous country. Having a mix of people with a diverse skill set coming to the garden workshops allows for an exchange of knowledge that would not be otherwise possible.

Using environmental justice has allowed us to critically examine where community garden policy is likely to fall short for providing a safe, comfortable, and educational space for newcomers. The efficacy of environmental justice must be further studied vis-à-vis newcomers use of community gardens. Specifically, how newcomer populations in cities are taken into account when planning and zoning for community gardens, and how municipalities can continue 
to improve these spaces. Current gaps in the literature surrounding precise numbers and demographics of who uses community gardens in Canada remain and must be further investigated to gain a clear understanding of improvements that can be made for specific community gardens and what municipalities can do to facilitate this.

More generally, when effectively planned and maintained, community gardens are spaces for newcomers to join a socially cohesive community and participate in an open and democratic spaces. The creation of further community gardens in cities with the intent of ensuring that they are safe and welcoming is an effective tool for social integration to occur in tandem with sustainable practices. Certainly, community gardens are not the only tool that can be used for integration of newcomers, but the numerous and holistic benefits they provide cannot be ignored. Spaces of integration, knowledge, sustainability, and community-building that have been shown to provide enhancements for the neighbourhood generally means that community gardens should be used to their full potential.

More research is needed to evaluate municipal community garden policies that list diversity and integration as a goal to determine whether the municipalities are following through with ensuring that community gardens are indeed spaces that foster inclusion from the perspective of newcomers. Further, using longitudinal studies, assessing how municipalities can foster social inclusion for newcomers using policy should be conducted. 


\section{REFERENCES}

Agustina, I. \& Beilin, R. (2012). Community gardens: Space for interactions and adaptations. Procedia - Social and Behavioral Sciences, 36, 439-448.

Baker, L. E. (2004). Tending cultural landscapes and food citizenship in Toronto's community gardens. Geographical Review, 94(3), 305-325.

Brulle, R. J., \& Pellow, D. N. (2006). Environmental justice: Human health and environmental inequalities. Annual Review of Public Health, 27(1), 103-124.

Bullard, R. D. (1994). Unequal protection: Environmental justice and communities of color. Sierra Club Books,.

Bullard, R. D. (2005). The quest for environmental justice: Human rights and the politics of pollution (1st ed.) Sierra Club Books.

City of Hamilton. (n.d.) City Councillors. Retrieved August 15, 2018, from https://www.hamilton.ca/council-committee/mayor-councillors/city-councillors

City of Hamilton. (2010). Community Garden Policy (PW 10044) - (City Wide). Retrieved from http://www.hamilton.ca/CityDepartments/PublicWorks/Parks/Horticulture/CommunityGa rdens.htm

City of Hamilton. (2011). Community Garden Coordinator Position. Retrieved August 08, 2018, from http://www2.hamilton.ca/NR/rdonlyres/ABE85BED-D9B3-4435-915B8852136648F2/0/Dec12EDRMS_n243771_v1_8_3_BOH11001_a_CCommunity_Garde ns_Coord.pdf

City of Toronto. (2009). Community gardens in the city of Toronto. Retrieved from http://www.toronto.ca/parks/programs/community.htm

City of Toronto. (2018). Community Gardens. Retrieved May 13, 2018 from 
https://www.toronto.ca/explore-enjoy/parks-gardens-beaches/gardens-andhorticulture/urban-agriculture/community-gardens/

City of Toronto. (2018b). Allotment Gardens. Retrieved June 20, 2018, from https://www.toronto.ca/explore-enjoy/parks-gardens-beaches/gardens-andhorticulture/urban-agriculture/allotment-gardens/

City of Vancouver. (2005). Operational guidelines for community gardens on city owned land other than parks. Retrieved August 03, 2018, from http://vancouver.ca/commsvcs/socialplanning/initiatives/foodpolicy/projects/pdf/commga rdensguide.pdf hvbv

Corrigan, M. P. (2011). Growing what you eat: Developing community gardens in baltimore, maryland. Applied Geography, 31(4), 1232-1241. doi:10.1016/j.apgeog.2011.01.017

DeLind, L. B. (2002). Place, work, and civic agriculture: Common fields for cultivation.Agriculture and Human Values, 19(3), 217-224. doi:10.1023/A:1019994728252

Egoz, S., \& De Nardi, A. (2017). Defining landscape justice: The role of landscape in supporting wellbeing of migrants, a literature review. Landscape Research, 42(sup1), S74-S89. doi:10.1080/01426397.2017.1363880

Emmett, R. (2011). Community gardens, ghetto pastoral, and environmental justice.Interdisciplinary Studies in Literature and Environment, 18(1), 67-86. doi:10.1093/isle/isq127

Gerodetti, N., \& Foster, S. (2016). "Growing Foods From Home": Food production, migrants and the changing cultural landscapes of gardens and allotments. Landscape Research, 41(7), 808. doi:10.1080/01426397.2015.1074169 
Ghose, R., \& Pettygrove, M. (2014). Urban community gardens as spaces of citizenship.Antipode, 46(4), 1092-1112. doi:10.1111/anti.12077

Gibson-Wood, H. \& Wakefield. S. (2013). "Participation", white privilege and environmental justice: Understanding environmentalism among Hispanics in Toronto. Antipode, 45(3), 641-662. DOI: 10.1111/j.1467-8330.2012.01019.x

Glover, T. D., Parry, D. C., \& Shinew, K. J. (2005). Building relationships, accessing resources: Mobilizing social capital in community garden contexts. Journal of Leisure Research, 37(4), 450-474. Retrieved from http://ezproxy.lib.ryerson.ca/login?url=https://search-proquestcom.ezproxy.lib.ryerson.ca/docview/201183272?accountid=13631

Gould, K. A., \& Lewis, T. L. (2009). Twenty lessons in environmental sociology (1st ed.) Oxford University Press.

Hamilton Community Garden Network. (n.d.). Garden Directory. Retrieved July 04, 2018, from http://hcgn.ca/garden-directory/

Hancock, T. (2001) People, partnerships and human progress: building community capital. Health Promotion International, 16, 275-280.

Harris, N., Minniss, F. R., \& Somerset, S. (2014). Refugees connecting with a new country through community food gardening. International Journal of Environmental Research and Public Health, 11, 9202-9216. DOI:10.3390/ijerph110909202

Holifield, R., Porter, M., \& Walker, G. (2009). Introduction spaces of environmental justice: Frameworks for critical engagement. Antipode, 41(4), 591-612.

Holifield, R. (2001). Defining Environmental Justice and Environmental Racism. Urban Geography, 22(1), 78-90. doi:10.2747/0272-3638.22.1.78 
Hondagneu-Sotelo, P. (2017). At home in inner-city immigrant community gardens. Journal of Housing and the Built Environment, 32(1), 13-28. doi:10.1007/s10901-015-9491-0

Jermé, E. S., \& Wakefield, S. (2013). Growing a just garden: Environmental justice and the development of a community garden policy for Hamilton, Ontario. Planning Theory \& Practice, 14(3), 295-314. doi:10.1080/14649357.2013.812743

Kremer, P., \& DeLiberty, T. L. (2011). Local food practices and growing potential: Mapping the case of Philadelphia. Applied Geography, 31(4), 1252-1261. doi:10.1016/j.apgeog.2011.01.007

Litt, J. S., Soobader, M., Turbin, M. S., Hale, J. W., Buchenau, M., \& Marshall, J. A. (2011). The influence of social involvement, neighborhood aesthetics, and community garden participation on fruit and vegetable consumption. American Journal of Public Health, 101(8), 1466-1473. doi:10.2105/AJPH.2010.300111

Nouri-Sabzikar, H. (2016). Widening the circle: Racialized immigrants in Toronto's alternative food movement (Major Research Paper, Ryerson University

Pudup, M. B. (2008). It takes a garden: Cultivating citizen-subjects in organized garden projects. Geoforum, 39(3), 1228-1240. doi:10.1016/j.geoforum.2007.06.012

Sandler, R. D., \& Pezzullo, P. C. (2007). Environmental justice and environmentalism: The social justice challenge to the environmental movement MIT Press.

Schukoske, J. E. (2000). Community development through gardening: State and local policies transforming urban open space. New York University Journal of Legislation and Public Policy, 3(2), 351-392.

Seto, D. (2011). Diversity and engagement in alternative food practice: Community gardens in Vancouver, B.C. (MA thesis, University of British Columbia). 
Shan, H., \& Walter, P. (2015). Growing everyday multiculturalism: Practice-based learning of Chinese immigrants through community gardens in Canada. Adult Education Quarterly, 65(1), 19;34;-34. doi:10.1177/0741713614549231

Shrader-Frechette, K. S. (2002). Environmental justice: Creating equity, reclaiming democracy Oxford University Press.

Statistics Canada. (2016) Census Profile, 2016 Census. Hamilton Census Division.

Statistics Canada. (2017) Table 17-10-0078-01. Annual demographic estimates by census metropolitan area, age and sex, based on the Standard Geographical Classification (SGC) 2011

Statistics Canada (2017). Immigration and Ethnocultural Diversity: Key Results from the 2016 Census. The Daily. Retrieved from https://www150.statcan.gc.ca/n1/dailyquotidien/171025/dq171025b-eng.htm.

Stewart, J. (2012). A true community garden gives green space to immigrants. StarPhoenix Retrieved from http://ezproxy.lib.ryerson.ca/login?url=https://search-proquestcom.ezproxy.lib.ryerson.ca/docview/1086551453?accountid=13631

Veen, E. J., Bock, B. B., Van den Berg, W., Visser, A. J., \& Wiskerke, J. S. C. (2016). Community gardening and social cohesion: Different designs, different motivations. Local Environment, 21(10), 1271-1287. DOI: 10.1080/13549839.2015.1101433

Ville de Montréal. (2005). Le cahier de gestion du programme des jardins communautaires. Montréal: Services des sports, des loisirs et du développement social-Direction de la cultura, des loisirs et du développement social. Montréal: Ville de Montréal.

Wakefield, S., Yeudall, F., Taron, C., Reynolds, J., \& Skinner, A. (2007). Growing urban health: Community gardening in south-east toronto. Health Promotion International, 22(2), 92- 
101. doi:10.1093/heapro/dam001

Young, I. M. (1990). Justice and the politics of difference Princeton University Press. 